\title{
Effect of Soil Loading Surcharge on its CBR Value
}

\author{
Robert Nini \\ University of Balamand \\ Balamand, El-Koura, Lebanon \\ robert.nini@balamand.edu.lb
}

\begin{abstract}
The upper subgrade of many countries is manly formed from a clayey soil. This kind of soil presents a weak California Bearing Ratio value when it is soaked. Scientists around the world always try to find a way to solve this problem, because it causes cracks and holes on highways. The normal CBR test is done by applying a continuous load after placing surcharge weight ring on the soil. The main purpose of this paper is to study the effect of vertical confinement caused by the surcharge ring on the soaked CBR of soil. For this purpose, five CBR tests are performed to each of the ten different soils collected from Lebanese territories. Each CBR test is performed with different ring loading ranging from no ring till four rings. At the same time, identifications tests are performed on these soils in order to classify them. The CBR test results are linked to the soil properties obtained from the identification tests. The analysis shows that the vertical confinement has a positive effect on the soaked CBR of clayey soils. In general, the CBR value increases as the number of ring loading increases. The synthesis of experimental results shows that the increment ratio of CBR for soil under a given number of rings is related to the liquid limit of the soil.
\end{abstract}

Keynotes: Confinement Pressure, CBR, Clay, Liquid limit, Increment Ratio, Loading Ring.

\section{Introduction}

In the past recent years, there has been a remarkable increase in road construction all around the world, especially in the Middle East. One of the most common issues faced by civil and road engineers is the bearing capacity of the soil being used as subbase and subgrade soil in road and terminal constructions. This is because in some countries soil being consisted by mostly clay. The reason behind clay causing such problems is that clay has a very low California Bearing Ratio value, especially under soaked conditions, and, therefore, causing continuous settlement. The California Bearing Ratio (CBR) is a penetration test performed on a soil in order to evaluate its mechanical strength. The test is basically performed by measuring the pressure needed to penetrate a soil with a piston of standard area. Then, this measured pressure is divided by the pressure required to achieve an equal penetration on a standard crushed rock material. The resulting ratio is the California Bearing Ratio. However, the soil tested should be under its optimum unit weight. Therefore, the Proctor test should be performed on the soil in order to find its optimum moisture content which is giving its optimum unit weight. According to ASTM specifications, before performing a CBR test, a surcharge ring loading is applied at the top of the compacted soil around the piston. This loading is a simulation of the overburden pressure usually caused by the weight of pavement on soil. This paper is studying the effect of the ring loading on the CBR value of soil. In order to achieve this, we performed five CBR tests on each of the ten different soils under different surcharge rings. The CBR test is performed on each soil, first without any loading, second, with one ring, then by two rings, then by three and finally by four rings. These soils were collected from different areas in Lebanon such as Ferzoul, Terbol, Taanayel, Rassieh, Wadi Arayesh, Houmin, Kafaroman, Shoukin, Kafartbnit and Zawtar. The first five villages are located in Zahleh region and the others are located in Nabatiyeh zone. At the same time, the identification tests were performed on our ten soils in order to evaluate their respective parameters. These parameters were analyzed in order to compare the behavior of different kind of soils and how their respective parameters affect their CBR values under different surcharge loadings. The results were carefully and accurately analyzed in order to get useful conclusions. This project consists of two main parts: experimental part and analysis part. The experimental part consists of performing two sets of experiments, the main tests and the identification tests. The main tests are mainly the Proctor test and the CBR test which are performed on the ten soils. The identification tests consist of specific gravity test, sieve analysis test, hydrometer test, Atterberg limits test and the classification test. These tests are important in order to connect the behavior of soil to their specific parameters. The 
synthesis part consists to collect all the results obtained from the experimental part and to analyze them in order to get conclusions

With time, many researchers tried to understand better the relation between the loading applied on the soil and the corresponded CBR value. In fact Razzouk et al [1] found strong correlation between the strength ratio of CBR under given surcharge and CBR under the standard surcharge. Furthermore, Razzouk et al [2], in other paper, developed an empirical equation relating the resilient modulus of soil at any soaking period to the unsoaked condition taking into account the effect of soaking period and surcharge weights. Also Senqupta et al [3] worked on the improvement of CBR of clayey subgrade using compacted fly ash layer. Moreover, Sas et al [4], had determined under repeated loading CBR, the resilient modulus for the lime stabilized clay.

\section{Experimental Part}

As mentioned before, the CBR test is performed on soil compacted under its optimum unit weight. Therefore, Proctor tests [5], should be done first on the ten soils in order to find their optimum moisture content giving their optimum unit weight. Once we performed Proctor test, we will perform the CBR test [6], on soil compacted under its maximum unit weight. Moreover the identification tests should be done in order to find all the soil characteristics which will be used to analyze the results and to understand more their behavior.

\subsection{CBR Tests}

To perform the CBR tests, we performed Proctor tests in order to compact the ten soils under their optimum unit weight. Five Molds of each soil are compacted at their respective optimum moisture content. The molds are soaked for four days, and, then, each mold is tested under CBR with different ring loadings. The first with no ring loading, the second with one ring loading, thirdly, with two rings loading. Fourthly, with three rings loading and finally, with four rings loadings. The results of five CBR tests on each soil under different surcharge rings are collected in a chart showing the pressure applied to the soil in KiloPascal versus the penetration of the piston in inches. According to the ASTM standards, the CBR test should be performed under two loading rings having weight of $44.5 \mathrm{~N}$. In order to study the effect of the surcharge applied on the soil on its CBR value, the below figures are prepared.

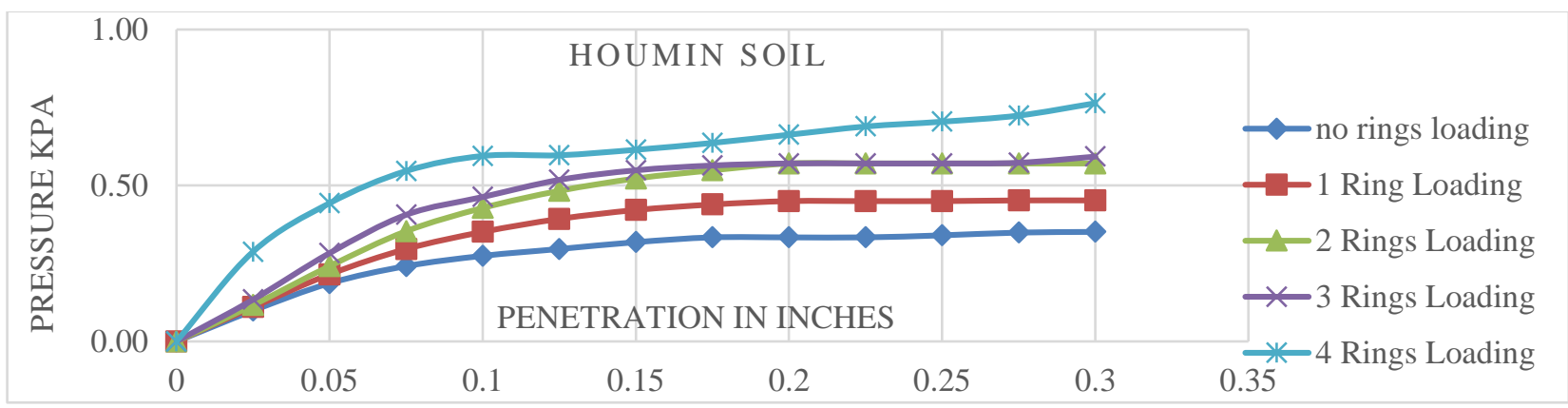

Fig. 1: Pressure versus penetration of Houmin soil sample under continuous load with different rings loadings.

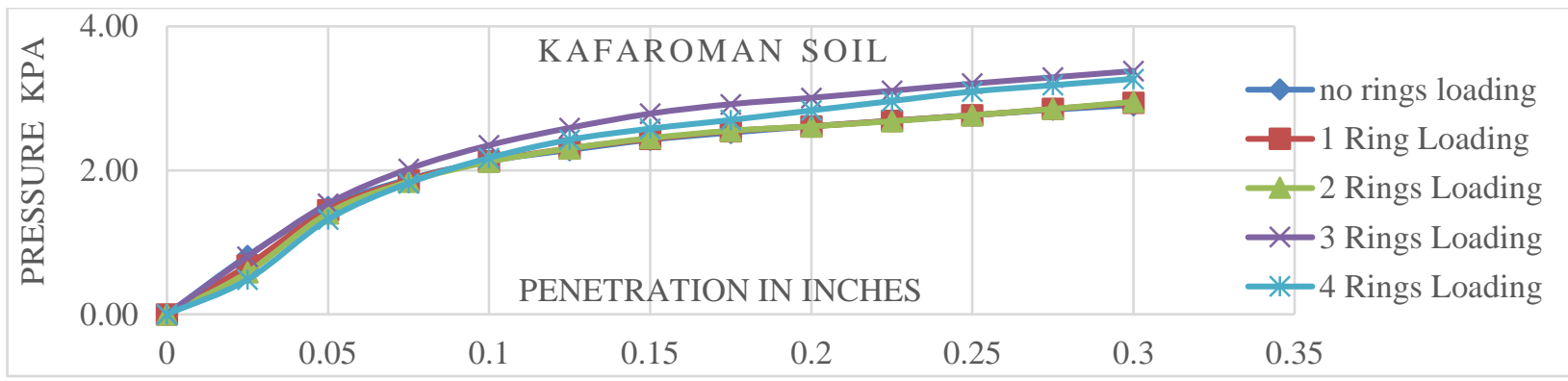

Fig. 2: Pressure versus penetration of Kafaroman soil sample under continuous load with different rings loadings. 


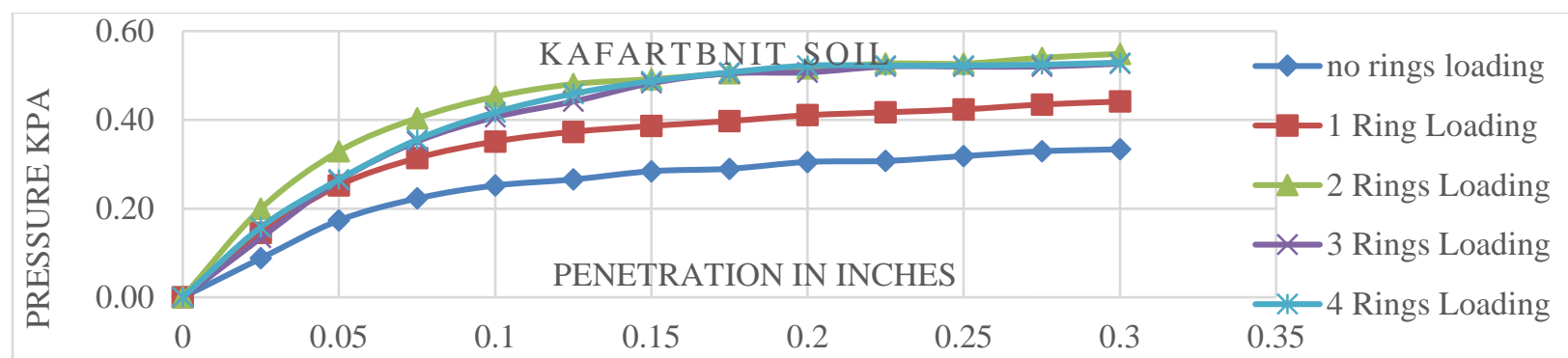

Fig. 3: Pressure versus penetration of Kafartbnit soil sample under continuous load with different rings loadings.

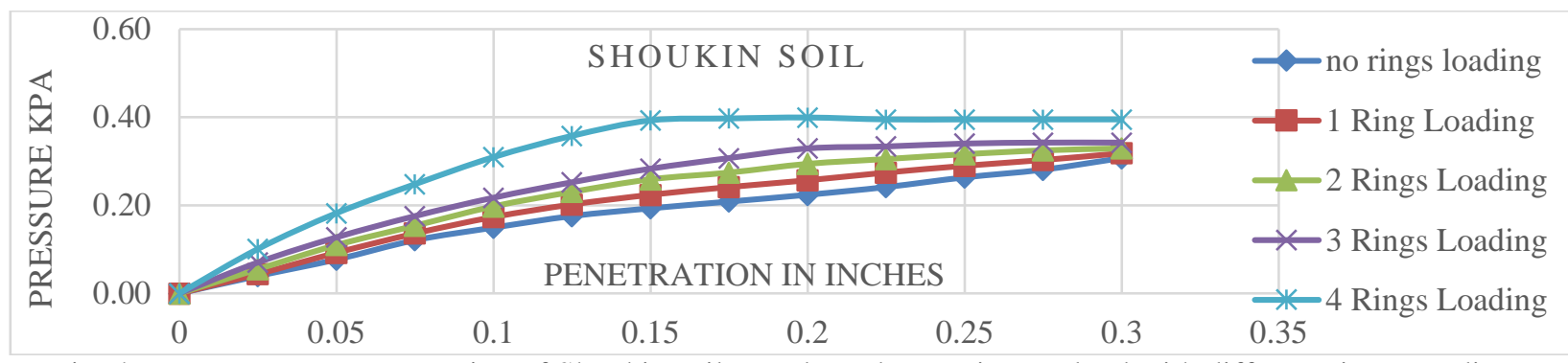

Fig. 4: Pressure versus penetration of Shoukin soil sample under continuous load with different rings Loadings.

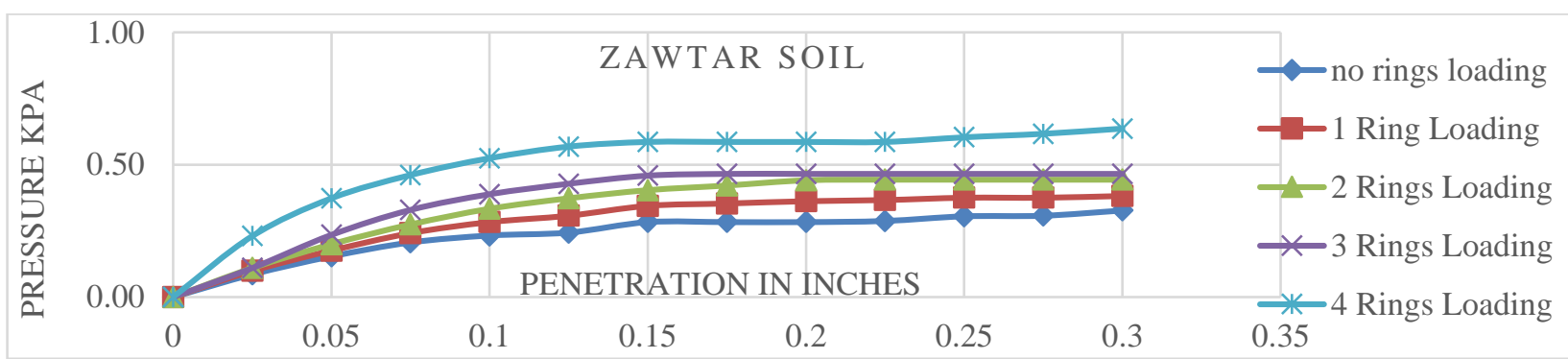

Fig. 5: Pressure versus penetration of Zawtar soil sample under continuous load with different rings loadings.

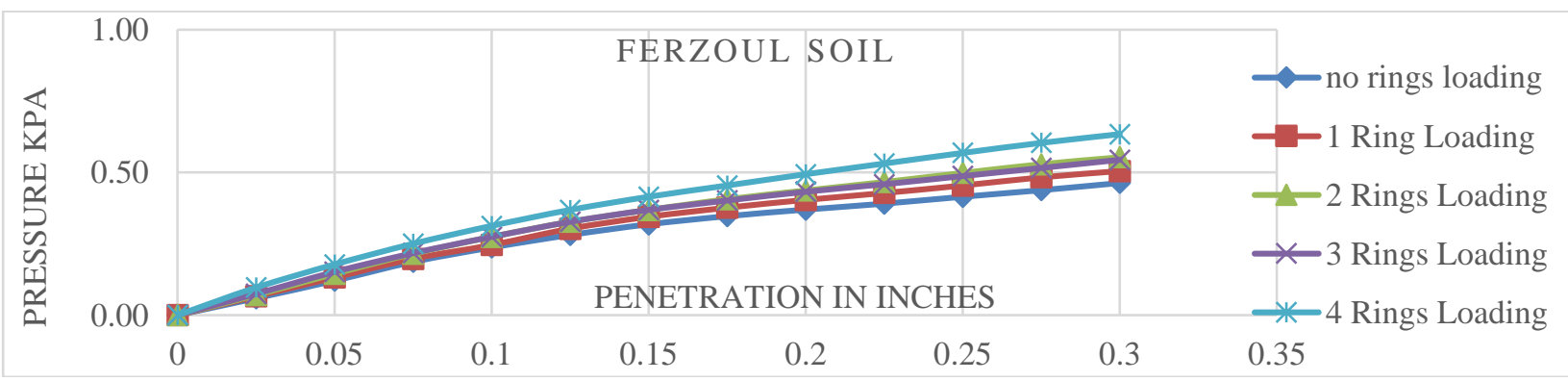

Fig. 6: Pressure versus penetration of Ferzoul soil sample under continuous load with different rings loadings.

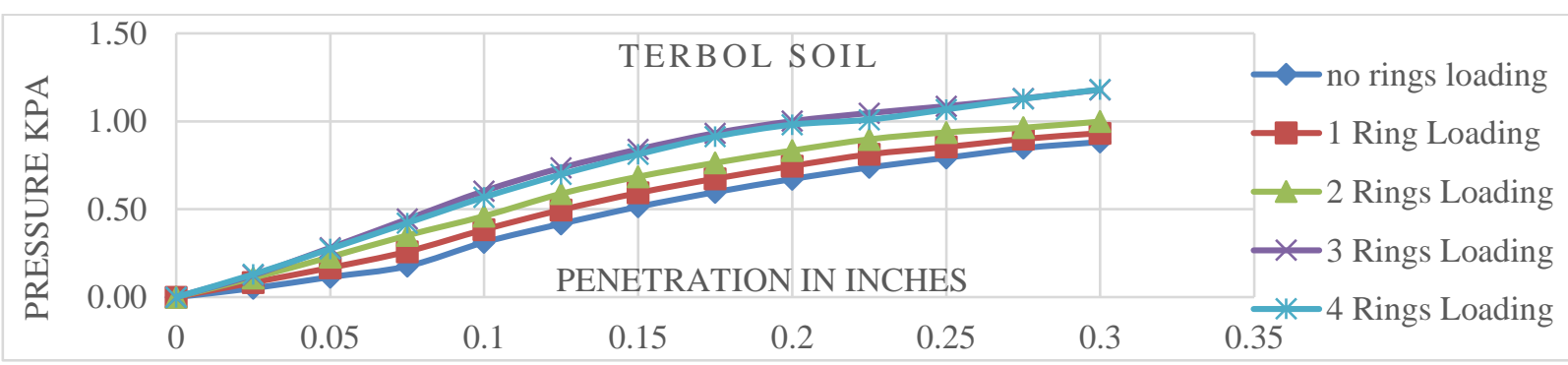

Fig. 7: Pressure versus penetration of Terbol soil sample under continuous load with different rings loadings. 


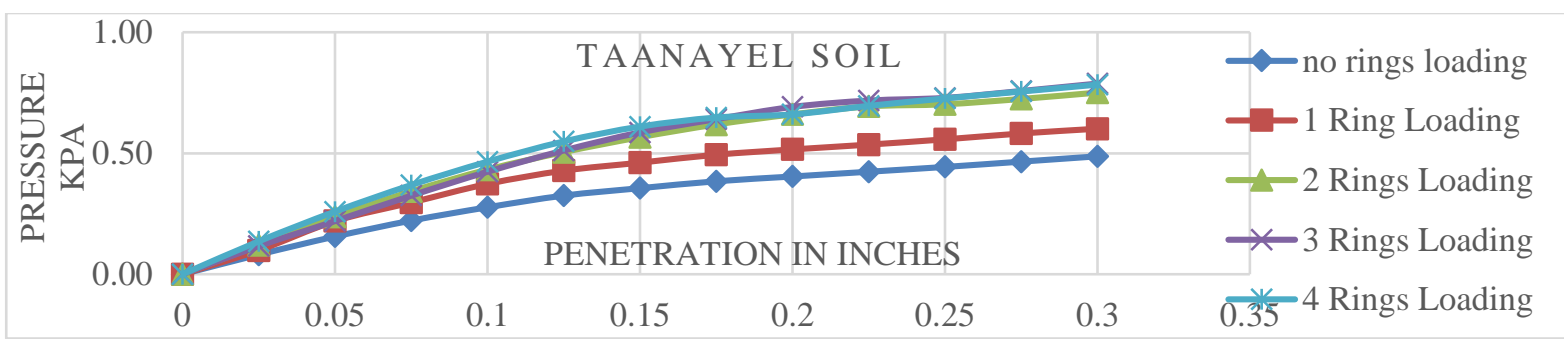

Fig. 8: Pressure versus penetration of Taanayel soil sample under continuous load with different rings loadings.

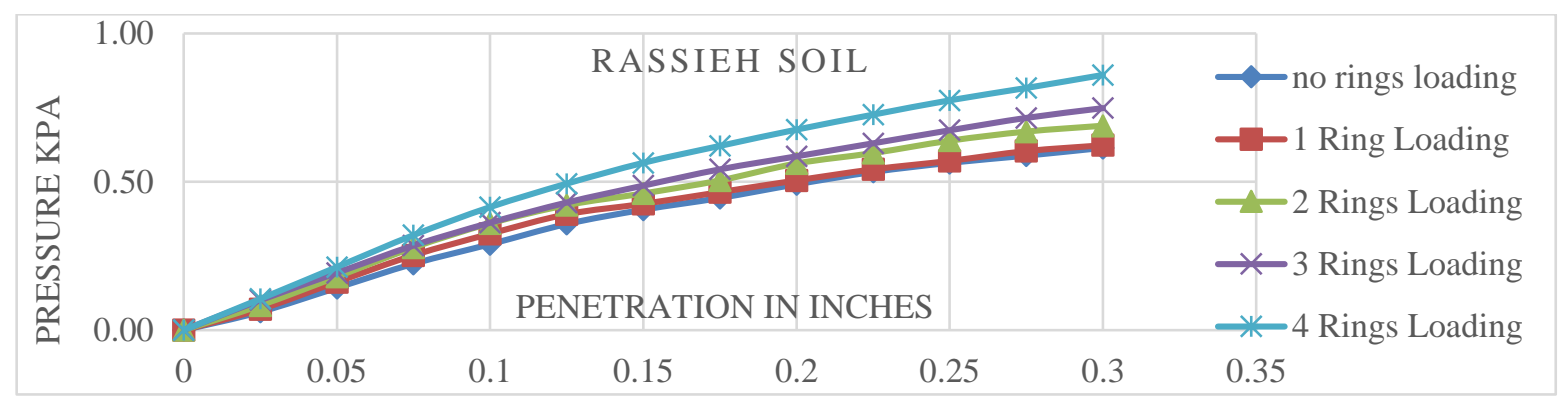

Fig. 9: Pressure versus penetration of Rassieh soil sample under continuous load with different rings loadings.

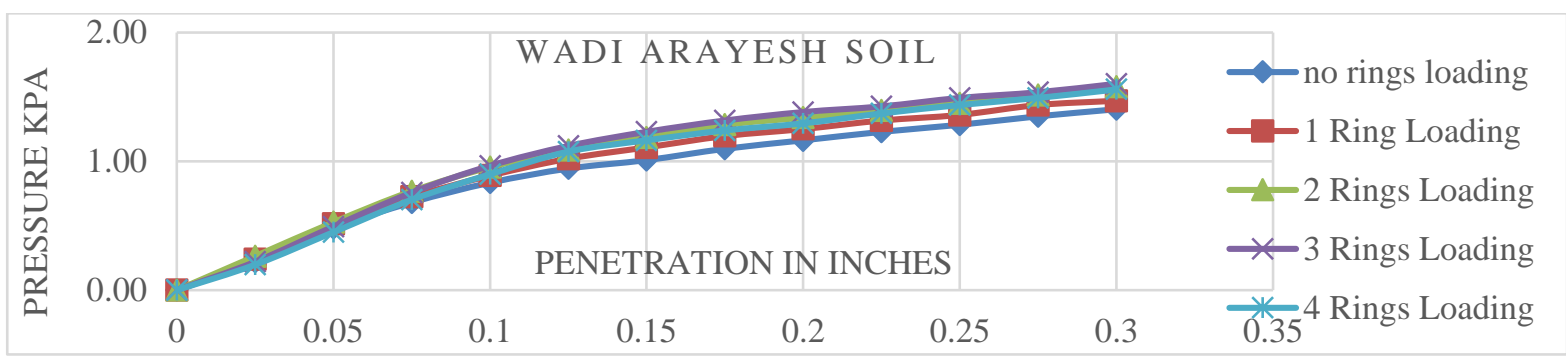

Fig. 10: Pressure versus penetration of Wadi Arayesh soil sample under continuous load with different rings loadings.

\subsection{Identification Tests}

After finishing the Proctor and CBR tests, we performed the identification tests including the Atterberg limits [7],, the sieve analysis [8], the specific gravity [9], the hydrometer test [10] giving us the sand fraction, the silt fraction and the clay fraction in order to start the analysis part. The identification test results are shown in table 1 below.

\section{Analysis of the Experimental Results}

In order to evaluate the effect of adding rings loading on the CBR value, we calculated in table 2 the increment of $\mathrm{CBR}$ value which obtained after placement of more than one ring on the top of the soil prior to perform the CBR test.

This increment of CBR value is a ratio between the CBR values of soil under a given number of rings divided by the CBR of the same soil under no rings loading. The next table shows the average increment of CBR under different loading cases ranging from one ring loading to four rings. We are using the average increment due to the fact that we have a minimum two values of CBR for each soil, one under 0.1 inch penetration and the other under 0.2 inch penetration. 
Table 1: Identification test results for the ten used soil samples.

\begin{tabular}{|c|c|c|c|c|c|c|c|c|c|c|c|}
\hline Sample & Soil location & $\begin{array}{c}\text { Plastic } \\
\text { Limit } \\
(\%)\end{array}$ & $\begin{array}{c}\text { Liquid } \\
\text { Limit } \\
(\%)\end{array}$ & $\begin{array}{l}\text { Plasticity } \\
\text { Index } \\
(\%)\end{array}$ & $\begin{array}{l}\text { Specific } \\
\text { gravity }\end{array}$ & $\begin{array}{c}\text { OMC } \\
(\%)\end{array}$ & $\begin{array}{c}\gamma_{\text {drymax }} \\
\left(\mathrm{kN} / \mathrm{m}^{3}\right)\end{array}$ & $\begin{array}{c}\text { Sand } \\
\text { Fraction } \\
(\%)\end{array}$ & $\begin{array}{l}\text { Silt and } \\
\text { Clay } \\
\text { fraction } \\
(\%)\end{array}$ & $\begin{array}{c}\text { Clay } \\
\text { Fraction } \\
(\%)\end{array}$ & $\begin{array}{l}\text { Silt } \\
\text { Fraction } \\
(\%)\end{array}$ \\
\hline S1 & Houmin & 44.82 & 60.76 & 15.94 & 2.55 & 20.78 & 17.43 & 14.14 & 50.35 & 31.28 & 19.07 \\
\hline S2 & Kafaroman & 19.15 & 33.8 & 14.65 & 2.64 & 9.7 & 20.18 & 48.3 & 47.82 & 24.01 & 23.81 \\
\hline S3 & Kafartbnit & 33.33 & 52.74 & 19.41 & 2.73 & 22.54 & 16.03 & 9.56 & 88.53 & 62.01 & 26.52 \\
\hline S4 & Shoukin & 23.6 & 56.93 & 33.33 & 2.51 & 18.28 & 16.41 & 11.17 & 84.71 & 52.44 & 32.27 \\
\hline S5 & Zawtar & 43.85 & 57.94 & 14.09 & 2.54 & 21.2 & 10.18 & 6.94 & 76.99 & 53.99 & 23 \\
\hline S6 & Ferzoul & 33 & 48.43 & 15.43 & 2.72 & 19.15 & 17.24 & 13.95 & 85.43 & 43.39 & 42.04 \\
\hline S7 & Terbol & 33.33 & 50.19 & 16.86 & 2.66 & 16.04 & 17.49 & 16.46 & 77.57 & 38.72 & 38.85 \\
\hline S8 & Taanayel & 25.11 & 42.01 & 16.9 & 2.76 & 11.61 & 19.51 & 18.91 & 71.12 & 32.19 & 38.93 \\
\hline S9 & Rassieh & 27.38 & 39.4 & 12.02 & 2.61 & 14.05 & 18.54 & 22.45 & 68.89 & 32.07 & 36.82 \\
\hline $\mathrm{S} 10$ & wadiArayesh & 26.9 & 37.18 & 10.28 & 2.67 & 13.82 & 18.76 & 23.04 & 71.62 & 36.49 & 35.13 \\
\hline
\end{tabular}

Table 2: Average increment ratio of CBR value under given loading rings relatively to no loading ring.

\begin{tabular}{|c|c|c|c|c|}
\hline & $\begin{array}{c}\text { Avg. inc. } \\
\text { 1 ring loading }\end{array}$ & $\begin{array}{c}\text { Avg. inc. 2 } \\
\text { ring loading }\end{array}$ & $\begin{array}{c}\text { Avg. inc. 3 } \\
\text { rings loading }\end{array}$ & $\begin{array}{c}\text { Avg. inc. 4 rings } \\
\text { loading }\end{array}$ \\
\hline S1 & 1.28 & 1.56 & 1.65 & 2.22 \\
\hline S2 & 1.00 & 1.00 & 1.12 & 1.02 \\
\hline S3 & 1.39 & 1.78 & 1.80 & 1.82 \\
\hline S4 & 1.13 & 1.28 & 1.43 & 1.89 \\
\hline S5 & 1.22 & 1.43 & 1.57 & 2.18 \\
\hline S6 & 1.08 & 1.28 & 1.36 & 1.51 \\
\hline S7 & 1.23 & 1.47 & 1.78 & 1.74 \\
\hline S8 & 1.29 & 1.37 & 1.39 & 1.47 \\
\hline S9 & 1.07 & 1.18 & 1.26 & 1.43 \\
\hline S10 & 1.07 & 1.14 & 1.14 & 1.08 \\
\hline Average & 1.176 & 1.349 & 1.45 & 1.636 \\
\hline
\end{tabular}

Many remarks can be given concerning the results analysis. In fact, the results of soil CBR increment value under different loadings tabulated in the previous table, had shown that under all type of loading and for all soils, always there is increasing of CBR value while increasing the loading rings applied on the soil. All the values are larger than 1 and all the CBR values are proportional to the number of rings loading applied on the top of the soil. In fact, the average value of CBR increment for all soils ranges between 1.176 under one loading ring and 1.636 under four loading rings. This means that applying a confinement pressure on the soil is always beneficial to its mechanical resistance.

We found that the CBR increment of soil under four loading rings is perfectly proportional to its liquid limit value. In fact, the soil S1 showing the highest liquid limit value of $60.76 \%$, had showed also the highest CBR increment. The same for the soil S2 which showed the lowest CBR increment under four loading rings, had the lowest liquid limit value of 33.8 $\%$. By looking on the other soils, we can easily discover a perfect proportionality between the soil liquid limit values and their CBR increment under four loading rings. This can be explained by the fact that the soil with high liquid limit value can show the highest CBR values if it will be confined from all sides, which it is our case for these tests, where the soil is confined from all sides by the proctor steel mold and from the top by the loading rings. 
The soil S2 had showed the lowest CBR increment under all loading rings but it showed the highest CBR value and the highest proctor dry unit weight. This is explained by the fact that $\mathrm{S} 2$ has the maximum sand fraction and is classified as the most granular soil between the ten experienced soils. In fact, S2 which showed its highest densification under normal CBR will no more be affected by any other applied confinement. This is easily understood when knowing that the soil with highest CBR increment value $\mathrm{S} 1$ has the highest liquid limit.

\section{Conclusion}

After analysing all the experiments results, it was obvious to conclude that all the soils used in this research had showed an increasing of the CBR value once the loading on the soil surface was increased. Moreover, a proportional relation was found between the increment ratio of CBR under the maximum loading and the liquid limit of the soils. For this reason, it will be beneficial to any given soil to be confined in order to enhance its resistance to CBR penetration. This conclusion has a practical importance in highway engineering when an existing cohesive soil is working as a natural subgrade. In this case, using concrete borders as water channels walls may give the cohesive soil some confinement pressure leading to enhancement of its CBR value.

\section{References}

[1] S. S. Razouki and B. M. Salem, "Soaking-drying frequency effect on gypsum rich roadbed sand", International Journal of Pavement Engineering, vol. 15, no.10, pp. 933-939, 2014.

[2] S. S. Razouki and B. M. Salem,"Gypsum sand resilient modulus during cyclic soaking and drying," International Journal of Pavement Engineering, vol. 18, no.2, pp. 108-120, 2017.

[3] A. Senqupta, S. Mukherjee and A. Ghosh, "Improvement of Bearing Ratio of clayey subgrade using compacted fly ash layer," Geotechnical and Geological Engineering, vol. 35, no. 4, pp. 1885-1894, 2017

[4] W. Sas, A. Gluchowski and A. Szymanski, "Determination of the Resilient Modulus MR for the lime stabilized clay obtained from the repeated loading CBR," Annals of Warsaw University of Life Sciewnces-SGGW, vol. 44, no. 2, 2012. ISSN: $1898-8857$.

[5] ASTM Standard D698, "Standard Test Methods for Laboratory Compaction Characteristics of Soil Using Standard Effort" in ASTM International, pp. 78-88, 2001.

[6] ASTM Standard D1883, "Standard Test Methods for CBR of Laboratory-Compacted Soils," in ASTM International, pp. 170-177, 2001.

[7] ASTM Standard D4318, "Standard Test Methods for Liquid Limit, Plastic Limit and Plasticity Index of Soils," in ASTM International, pp. 561-574, 2001.

[8] ASTM Standard D422, "Standard Test Methods for Particle-Size Analysis of Soils," in ASTM International, 2001, pp. 10-17.

[9] ASTM Standard D854,"Standard Test Methods for Specific Gravity of Soil Solids by Water Pycnometer" in ASTM International, 2001, pp. 93-99.

[10] ASTM Standard D1140,"Standard Test Methods for Amount of Material in Soils Finer Than the No. 200 Sieve," in ASTM International, 2001, pp. 100-103. 